\title{
Pre-Competitive Period in Olympic Wrestling Athletes: Losing Weight, a Risk Factor
}

\author{
Sérgio Luiz Carlos dos Santos* \\ Federal University of Paraná, Center for Sports Talent Studies, Brazil \\ *Corresponding author: Sérgio Luiz Carlos dos Santos, Federal University of Paraná, Center for Sports Talent Studies, Brazil
}

\begin{tabular}{|c|c|}
\hline ARTICLE INFO & ABSTRACT \\
\hline Received: 蔧January 29, 2019 & \multirow{4}{*}{$\begin{array}{l}\text { The competition is the time where all training is put to the test; however, the pre- } \\
\text { competition period is common to see athletes performing severe hypo caloric diets, } \\
\text { dehydration techniques and even use of diuretic substances and even laxatives. This is due } \\
\text { to the fact that many athletes seek to fight in categories below their natural weight, seeking } \\
\text { weaker opponent. Weight loss, if done incorrectly and / or inappropriate way in time } \\
\text { malevolent triggers the body, such as immunosuppressant, hormonal imbalances, changes } \\
\text { in the cardiovascular system, electrolyte imbalance, impaired renal function, impaired } \\
\text { mental status and mood. The performance of the physical capacity of athletes subjected } \\
\text { to these kinds of practices, can be dramatically affected and can be minimized by recovery } \\
\text { time after weight by diet and used at that time. In this review we aim to expose a little bit } \\
\text { about the pre-competition reality highlight important, positive and negative practices of } \\
\text { losing weight fast but mainly points, answer the following question: really worth risking } \\
\text { the health for it? }\end{array}$} \\
\hline Published: 慧 February 07, 2019 & \\
\hline $\begin{array}{l}\text { Citation: Sérgio Luiz Carlos dos } \\
\text { Santos. Pre-Competitive Period in } \\
\text { Olympic Wrestling Athletes: Losing } \\
\text { Weight, a Risk Factor. Biomed J } \\
\text { Sci \& Tech Res 14(2)-2019. BJSTR. } \\
\text { MS.ID.002521. }\end{array}$ & \\
\hline $\begin{array}{l}\text { Keywords: Weight Loss; Pre- } \\
\text { Competition; Hormonal Imbalance }\end{array}$ & \\
\hline
\end{tabular}

\section{Introduction}

In Olympic wrestling, as in most combat sports except Fencing, there is a division by weight categories, aiming to balance athletes physical abilities, such as strength, and speed. It is common to see athletes reducing weight severely in an attempt to face weaker and lighter opponents. The big problem is that weight loss is usually not done gradually, scientifically and safely, and this brings about a new weight gain after the competition leaving the athlete in a routine of gain and constant loss of weight. This type of action can be harmful to the metabolism, causing health problems. The methods used in weight loss are usually dangerous, these are in general: dietary restrictions, dehydration (saunas, pharmacological resources, use of clothes that increase heat), intense exercise and even induction of vomiting. They are subterfuges used in the attempt to fit the desired category. According to Kiningham and Gorenflo [1], 72\% of athletes use at least one potentially harmful method to reduce weight; $52 \%$ use at least two dangerous methods, and $12 \%$ use at least five harmful methods each week. There is also evidence that athletes undergo binge eating episodes and exhibit traces of eating disorders, which tends to worsen as the athlete's competitive level increases [1].
In the United States, it was found that $90 \%$ of athletes usually reduce weight drastically in a period of less than a week. This cycle of weight gain and loss is initiated very early in the athletes, on average at 14 years, which can have consequences as hormonal dysfunctions and consequently, reduction in growth rate and physical development [2]. In recent research conducted in Ira, currently one of the highest levels of the World Olympics, whose goal was to compare the effects of rapid weight loss on white blood cells, high-performance fighters found important statements about the weight issue.

\section{Materials and Methods}

Twenty-two highly trained athletes (age 20-25 years) who participated voluntarily in the study were randomly divided into two groups: Group 1: rapid weight loss over a 48-hour period, and Group 2: gradual weight loss at over a period of 12 days. All individuals were asked to reduce their weight by 4 percent. Before and after the weight loss intervention, blood sampling was performed as well as physical performance tests (simulated fighting). The results showed that white blood cells increased 
significantly in both groups ( $p<0.05$ ). The amount of this increase was outside the normal range in the fast group but remained within the normal range in the gradual group. Neutrophils increased significantly while lymphocytes decreased significantly in the fast weight loss group $(\mathrm{p}<0.05)$.

\section{Results/Observations}

Comparing these two weight loss protocols it was demonstrated that the rapid weight loss method had more deleterious effects on the immune system of these fighters than those who followed a gradual weight loss plan. We also found supporting studies that techniques such as dehydration and dietary restriction can impair the physical and mental performance of the athlete [3].

\section{Discussion}

\section{Influence of Weight Loss on Aerobic Performance}

Studies have found that restrictive diets and / or dehydration can impair aerobic performance. Because it decreases the efficiency of the cardiorespiratory system, that is, it decreases the amount of oxygen transported in each heartbeat, decreases the muscular glycogen content and glycogen utilization rate and increases the loss of electrolytes, increases body temperature and even occurs difficulty of thermoregulation. However, if the athlete has time to feed and hydrate between the weighing and competition periods, this may not be affected as the endurance performance is significantly restricted after $5 \%$ weight reduction, but after five hours recovery values.

\section{Influence of Rapid Weight Loss on Force Production}

Regarding the effects of weight loss on strength, the results of the literature show some differences depending on the type of muscular action (isometric, isotonic or isokinetic), the muscle group evaluated and the weight loss protocol (with or without period of rehydration). Some studies have shown that maximum strength production is not affected by weight reduction, whether it has been achieved by dehydration or by "typical" fighter diets, even though there is no time to recover between weighing and the task. This suggests that after a recovery period the athletes will not present damage in the force.

Other studies have produced evidence to support the above hypothesis. They evaluated the isometric manual grip strength during a six-minute period (total of 180 maximum contractions, intercut for 1s rest) before and after 5\% weight loss followed by recovery period. Data from this study indicate that isometric strength in small muscle groups is not affected by rapid weight loss if athletes have a chance to recover after a diet. On the other hand, there is also important evidence that weight loss impairs the production of force, in this case a significant decrease in isokinetic strength of arms is observed, from pre-season to mid-season.

In addition, all measures of isokinetic strength have increased from the middle of the season to the period after the end of the season. In other words, the force measurements were smaller during the season compared to the holiday period, when fighters do not compete and consequently do not need to reduce weight. This demonstrates how force production can be negatively affected by rapid weight loss diets and, above all, by the repetitive cycle of gaining and losing weight that occurs during the competitive period. Therefore, this decrease in strength does not occur due to the acute reduction of weight, especially considering the time of recovery after weighing, but throughout the season and cycles of gain and loss of weight.

\section{Physiological Effects of Rapid Weight Loss}

With rapid weight loss there is a significant reduction in both fat mass and muscle mass. Branched chain amino acid supplementation promotes greater reduction of body fat, especially visceral fat, when weight reduction is gradual and obtained through a hypocaloric diet. And, among the main effects potentially harmful to health are: change in the concentration of some hormones, such as increased GH and decreased testosterone; decreased renal blood flow and glomerular filtration volume; increased electrolyte loss; decreased activity of the immune system; and temporary interruption of growth.

Another important issue is how often these athletes lose and regain weight quickly. This "win-lose" weight cycle is commonly called weight-cycling (WC). And rapid weight gain after rapid reduction is due to physiological adaptations whereby the body becomes more efficient in the use and storage of energy (increase in food efficiency). Combined with this increase in dietary efficiency is the decrease in the basal metabolic rate (BMR), which makes the next reductions increasingly difficult and requires increasing energy restrictions.

When energy expenditure has decreased and intake has increased, there will be evident considerable loss of fluid in all procedures for weight loss quickly. In dehydration, the ejection volume and the cardiac output are smaller and the reduced plasma volume limits the transport of oxygen to the active muscles. Rapid weight loss results in reduced blood volume, mainly due to the decrease in plasma volume. Reducing the plasma volume reduces the venous return.

In the case of moderate dehydration (3-5\% of body weight), the heart rate during a standardized sub-maximal exercise is disproportionately higher and the ejection volume is lower than in the non-dehydrated condition. When dehydration is more severe (6-7\% of body weight), there is a significant decrease in cardiac output and a compensatory increase in the arteriovenous oxygen difference, in an attempt to meet the oxygen consumption necessary to maintain the activity.

\section{Relationship Between Weight Recovery and Competitive Success}

Since the 1990s, several surveys have been carried out to verify the amount of weight that athletes can recover between official 
weighing and the beginning of the competition, and whether this recovery can affect performance in the competition. These investigations concluded that there was no difference in weight gain between the winning athletes and those who lost their matches. In addition, there was no statistically significant difference in weight gain between athletes who scored and those who could not rank among the first ones, indicating that the weight gain between weighing and competition did not favor those of more or less success.

It was also verified about the amount of weight recovered, which was not related to the success in the classification among the 3 first placed in the analyzed competitions and that the increase of the recovery time did not contribute to a greater weight gain. However, it is important to emphasize that the study under discussion was not generalized. In summary, although the literature data are still not conclusive, it can be stated that the amount of weight recovered, after weighing, has no relation to competitive success. However, among the most successful athletes, most reduce weight to compete, which seems totally paradoxical.

\section{Influence of Weight Loss on Anaerobic Performance}

Due to the great diversity of protocols for evaluating the behavior of the methods used for weight reduction, the time between weighing and the application of tests, there is still no conclusive answer regarding the influence of rapid weight loss on performance anaerobic and its implications on performance in fights. Rapid weight loss worsens anaerobic performance when there is no recovery time, or when this time is less than three hours. However, worsening performance may be prevented if the athlete engages in a high-carbohydrate diet during the energy restriction period or if he / she use gradual weight loss procedures (loss of a maximum of $1 \mathrm{~kg}$ per week). When the recovery time after weighing is greater than three hours, performance tends to return to baseline, especially if athletes consume high amounts of carbohydrate during that time.

However, it should be noted that in some case studies 16.5 hours of recovery were not sufficient to return the isokinetic performance from five minutes to normal. According to the official position of the American College of Sports Medicine, the reestablishment of hydro electrolytic homeostasis takes from 22 to 48 hours; muscle glycogen replacement may take up to 72 hours; and lean body mass recovery can take even longer. Studies show that Olympic wrestlers start the competition in a state of dehydration, even taking the recovery period after weighing. And four hours of rehydration are not sufficient to return plasma volume values and blood osmolality to normal, after weight loss of 4\% [4-13].

One possible explanation for the fact that most athletes are able to regain performance after approximately five hours of food and liquid intake is their high training status. According to some authors, the maintenance of performance, even with reduction of body weight, may be due to a possible training effect. The mechanisms responsible for performance decline after rapid body weight reduction are: 1) decrease in muscle glycogen stores caused by energy restriction accompanied by intense exercise; 2) reduction in glycogen utilization rate; 3) imbalance in the bicarbonate buffer system, caused by metabolic keto-acidosis, implying an increase in muscle acidosis; 4) increase in body temperature and greater difficulty in thermoregulation; and 5) loss of lean mass.

\section{Final Considerations}

It has been proven through bibliographical research that the harm of weight loss through extreme methods can be detrimental to athlete's health and performance. No athlete should use such techniques in attempting to fight in a weight category below his, since it is possible to achieve a conscious weight reduction using less aggressive methods over a longer period of time. It is necessary to publicize through lectures, scientific work, and qualification courses to raise awareness of athletes and coaches, so that this practice becomes less common, aiming at fairer and healthier competitions, preserving the longevity in the sport of these athletes.

\section{References}

1. Kinngham RB, Gorenflo DW (2001) Weight loss methods of high school wrestlers. Med Sci Sports Exerc 33(5): 810-813.

2. Roemich JN, Sinning WE (1997) Weight loss and effects on nutrition, growth, maturation, body composition and strength. J Appl Physiol 82(6): 1751-1759.

3. Ghaemi J, Rashidlamir A, Hosseini SR, Rahimi G (2014) The effect of rapid and gradual weight loss on some hematological parameters in trained wrestlers. International Journal of wrestling sciences 4(2).

4. Artioli (2006) Weight loss in grappling combat sports: Review and applied recommendations, 8(2).

5. Oppliger RA, Case HS, Horswill CA, Landry GL, Shelter AC (1996) American College of Sports Medicine Position Stand on weight loss in wrestlers. Med Science Sports Exercise 28(2): ix-xii.

6. Barroso BG, Silva JMA, Garcia AC, Ramos NCO, Martinelli MO, et al. (2011) Lesões músculo esqueléticas em atletas de luta olímpica. Acta Ortop Bras 19(2): 98-101.

7. Dimeff RJ, Houng DO (1999) Preventinng cauliflower ear with a modified tie through technique. Physian Sporsmed 17(3): 169-173.

8. Garrick JG, Webb DR (1990) Sports Injuries: Diagnosos and Management. Philadelphia, WB Saunders.

9. Grindstaff TL, Potach DH (2006) Prevention of common wrestling injuries. Strength Cond J 28(4): 20-28.

10. Horswill CA (1992) When wrestles slim to win. Physician Sportsmen 20(9): 91.

11. Respizzi Di S, Tavana R, Freschi M, Genesio L (2004) Le lesioni musculari nello sportivo. Trainer- Pianeta Isef 31: 52-56.

12. Ros A, Ignoto J, Garcia J, Abellan A (2005) Injure muscular of fight and their relationship with the techniques of fight. Revista Digital - Buenos Aires - Ano 10 - № 80 Janeiro.

13. Ros A, Gomez B (2004) Ignoto, J. Lucha olímpica: lesiones más frecuentes. Revista Digital - Buenos Aires - Ano 10 - № 73 - Junho. 
ISSN: 2574-1241

DOI: 10.26717.BJSTR.2019.14.002521

Sérgio Luiz Carlos dos Santos. Biomed J Sci \& Tech Res

(c) (i) This work is licensed under Creative

Submission Link: https://biomedres.us/submit-manuscript.php

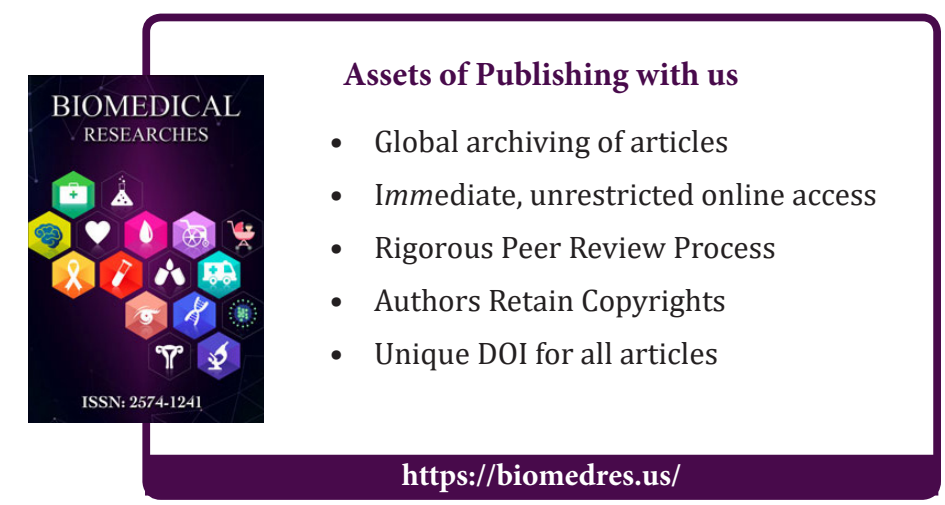

